\title{
Clinical Criteria for Airway Assessment: Correlations with Laryngoscopy and Endotracheal Intubation Conditions
}

\author{
Gustavo Henrique S. Wanderley ${ }^{1}$, Luciana Cavalcanti Lima ${ }^{2,3,4}$, Tânia Cursino de Menezes Couceiroo ${ }^{2,5,6}$, \\ Waston Vieira Silva ${ }^{2}$, Raquel Queiroz G. A. Coelho ${ }^{2}$, Andrea Cavalcanti C. Lucena ${ }^{7}$, \\ Anne Danielle Santos Soares ${ }^{2}$
}

\begin{abstract}
${ }^{1}$ Agreste Regional Hospital, Caruaru, Brazil; ${ }^{2}$ Instituto de Medicina Integral Professor Fernando Figueira (IMIP), Recife, Brazil; ${ }^{3}$ State University of São Paulo (UNESP), São Paulo, Brazil; ${ }^{4}$ Faculdade Pernambucana de Saúde, Recife, Brazil; ${ }^{5}$ Medical Residency Program in Anesthesiology, IMIP, Recife, Brazil; ${ }^{6}$ Neuropsychiatry and Behavioral Science, Federal University of Pernambuco, Recife, Brazil; ${ }^{7}$ Brazilian Society of Anesthesiology Accredited Teaching and Training Center, IMIP, Recife, Brazil.

Email: taniacouceiro@yahoo.com.br
\end{abstract}

Received June $27^{\text {th }}, 2013$; revised July $27^{\text {th }}, 2013$; accepted August $15^{\text {th }}, 2013$

Copyright (C) 2013 Gustavo Henrique S. Wanderley et al. This is an open access article distributed under the Creative Commons Attribution License, which permits unrestricted use, distribution, and reproduction in any medium, provided the original work is properly cited.

\begin{abstract}
Difficult intubation, inadequate ventilation and esophageal intubation are the principal causes of death or brain damage related to airway manipulation. The objective of this cross-sectional study was to correlate a preanesthetic evaluation that may be capable of predicting a difficult intubation with the conditions encountered at laryngoscopy and endotracheal intubation. Eighty-one patients submitted to general anesthesia were evaluated at a preanesthetic consultation according to the modified Mallampati classification, the Wilson score and the American Society of Anesthesiologists (ASA) difficult airway algorithm. Findings were then correlated with the Cormack-Lehane classification and with the number of attempts at endotracheal intubation. No statistically significant correlations were found between the patients' Mallampati classification and their Cormack-Lehane grade or between the Mallampati classification and the number of attempts required to achieve endotracheal intubation. Laryngoscopy proved difficult in four patients and in all of these cases the Wilson score had been indicative of a possibly difficult airway, highlighting its good predicting sensitivity. However, the specificity of this test was low, since another 24 patients had the same Wilson score but were classified as Cormack-Lehane I/II. Moreover, two patients who had a Wilson score $\geq 4$ were also classified as Cormack-Lehane grade I/II. The study concluded that the Wilson score, although seldom used in clinical practice, is a highly sensitive predictor of a difficult airway; its specificity, however, is low.
\end{abstract}

Keywords: Preanesthetic Evaluation; Respiratory System; Airway; Endotracheal Intubation; Measurement Techniques; Mallampati; Wilson; Cormack-Lehane

\section{Introduction}

Difficult airway management is one of the principal challenges faced by anesthesiologists in their routine practice. Data published by the American Society of Anesthesiologists (ASA) show that, despite the decline registered over recent decades, adverse respiratory events were involved in $32 \%$ of all lawsuits raised against anesthesiologists in the 1990s. Difficult intubation, inadequate ventilation and esophageal intubation were the principal factors responsible for death or brain damage [1].
Different clinical parameters have been proposed for preoperative airway assessment. In 1985, Mallampati et $a l$. introduced a scoring system based on the visibility of the oropharyngeal structures, which was later modified into four classes by Samsoon and Young in 1987 [2]. Wilson developed a scoring system based on the sum of constitutional and anatomical characteristics, and other authors evaluated indexes calculated according to the distances between anatomical structures (thyromental distance, sternomental distance and interincisor distance) $[3,4]$. The American Society of Anesthesiologists published an algorithm for a difficult airway and listed 11 
routine preoperative tests with their respective undesirable results (possible predictors of a difficult airway) [5]. Nevertheless, the diagnostic accuracy of airway assessment tests has varied significantly in the different studies, probably as a function of variations in the incidence of difficult intubation, which may be explained by the constitutional differences in the individual patients and in the populations evaluated [3].

The objective of the present study was to correlate the findings of the modified Mallampati classification, the Wilson score and the ASA difficult airway algorithm with the conditions encountered at conventional direct laryngoscopy (Cormack-Lehane classification) and at endotracheal intubation.

\section{Methods}

Following approval by the institution's internal review board, a cross-sectional study was conducted at the Instituto de Medicina Integral Professor Fernando Figueira (IMIP), Recife, Pernambuco, Brazil, between December 2010 and November 2011.

The study inclusion criteria consisted of patients of either sex in the 18 - 65 year age group, with an ASA physical status classification of $\mathrm{P} 1, \mathrm{P} 2$ or $\mathrm{P} 3$, who required endotracheal intubation for general anesthesia. Pregnant women, patients with cognitive deficiencies or with any pathology that could alter the anatomy of the face or neck were excluded.

Following selection, and after all the patients had signed an informed consent form, a preanesthetic evaluation was performed by the anesthesiologist and/or a resident anesthesiologist.

At the time of airway assessment, three data sets were obtained: the patient's modified Mallampati classification (I, II, III or IV) (Figure 1); the Wilson score, which takes five factors into consideration: weight, head and neck mobility, jaw movement, retrognathia and buck teeth (Table 1); and finally, the ASA difficult airway algorithm, in which each undesirable result is awarded one point (Table 2 ).

In the operating theater, the patient was placed in the dorsal decubitus position and in the sniffing position,

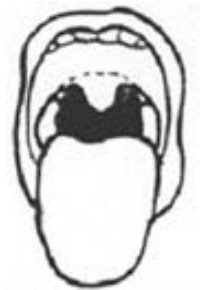

I

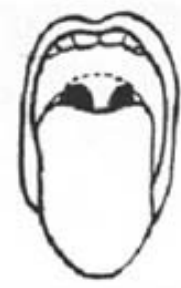

II

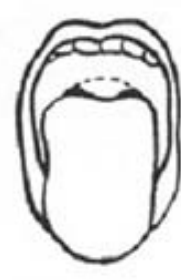

III

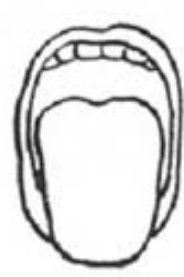

IV
Figure 1. Modified mallampati classification. which consists of flexing the neck and then extending the head. A pillow is used to support the head sufficiently high so as to ensure that the external auditory meatus and the sternal notch are aligned horizontally [6].

With the patient duly in position, general anesthesia was induced with the standard drugs used in this institute. A neuromuscular blocking drug, atracurium, was then given to all patients at a dose of $0.5 \mathrm{mg} / \mathrm{kg}$. Once the 5 minute latency period was over, laryngoscopy was performed using a conventional laryngoscope with a Macintosh blade \# 3, 4 or 5, and the patient was then classified as Cormack-Lehane grade I, II, III or IV (Figure 2). Due to the fact that the IMIP is a teaching institute, laryngoscopy was performed by the resident anesthesiologist scheduled for that particular procedure. This resident may have been in the first, second or third year of the residency program. Classification was then confirmed by the chief anesthesiologist. In cases of discordance, the classification suggested by the chief anesthesiologist prevailed. Endotracheal intubation was then performed, with the number of attempts required until successful intubation, or the impossibility of endotracheal intubation, being recorded.

Data concerning sex, weight, height, body mass index (BMI) and ASA physical status classification were recorded. The variables analyzed were: the modified Mallampati class, the Wilson score, the ASA difficult airway algorithm, the Cormack-Lehane grade and the number of endotracheal intubation attempts.

For the purposes of data analysis, the patients were subdivided into groups for each index: Mallampati I/II or Mallampati III/IV; a Wilson score of $0 / 1$ or $2 / 3$ or $\geq 4$; ASA difficult airway algorithm $\leq 6$ or $\geq 7$; Cormack-Lehane grade I/II or III/IV; number of attempts at intubation: $\leq 2$ or $>2$ or failed intubation. The Epi Info software program, version 3.5.3 was used and Fisher's exact test and the chi-square test were applied in the statistical analysis. Results with p-values $<0.05$ were considered statistically significant.

\section{Results}

The sample consisted of 81 patients, more than half of whom were female. Mean age was 44 years and mean BMI was 27. The predominant ASA physical status classification was I/II (Table 3).

A Mallampati classification of I/II was found in 52 pa-

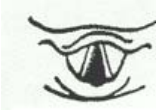

I

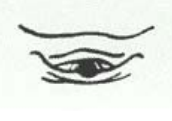

II

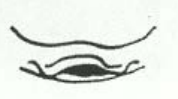

III

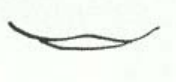

IV
Figure 2. Cormack-lehane classification. 
Table 1. The Wilson score method.

\begin{tabular}{|c|c|}
\hline Risk Factors & Score Points ${ }^{*}$ \\
\hline \multicolumn{2}{|l|}{ Weight } \\
\hline$<90 \mathrm{~kg}$ & 0 \\
\hline $90-110 \mathrm{~kg}$ & 1 \\
\hline$>110 \mathrm{~kg}$ & 2 \\
\hline \multicolumn{2}{|c|}{ Mobility of the head and neck } \\
\hline \multicolumn{2}{|c|}{ (Angle formed between the positions of greatest extension and greatest flexion of the neck) } \\
\hline$>90^{\circ}$ & 0 \\
\hline$\sim 90^{\circ}$ & 1 \\
\hline$<90^{\circ}$ & 2 \\
\hline \multicolumn{2}{|l|}{ Jaw movement } \\
\hline \multicolumn{2}{|c|}{ IO: maximum interincisal opening } \\
\hline \multicolumn{2}{|c|}{ SLux: Jaw subluxation and maximum forward protrusion of the lower incisors beyond the upper incisors. } \\
\hline IO $>5 \mathrm{~cm}$ or SLux $>0$ & 0 \\
\hline $\mathrm{IO}<5 \mathrm{~cm}$ or SLux $=0$ & 1 \\
\hline $\mathrm{IO}<5 \mathrm{~cm}$ or $\mathrm{SLux}<0$ & 2 \\
\hline \multicolumn{2}{|l|}{ Retrognathia } \\
\hline Absent & 0 \\
\hline Moderate & 1 \\
\hline Severe & 2 \\
\hline \multicolumn{2}{|l|}{ Buck teeth } \\
\hline Absent & 0 \\
\hline Moderate & 1 \\
\hline Severe & 2 \\
\hline
\end{tabular}

Scores $\geq 2$ and $\leq 4=$ a possibly difficult intubation; $>4$ = often difficult intubation.

Table 2. Airway assessment and undesirable results: ASA predictors.

\begin{tabular}{|c|c|}
\hline Parameters & Undesirable Results \\
\hline 1. Length of upper incisors & Relatively long \\
\hline $\begin{array}{l}\text { 2. Relation of maxillary and mandibular incisors } \\
\text { during normal jaw closure }\end{array}$ & $\begin{array}{l}\text { Prominent "overbite" } \\
\text { (maxillary incisors anterior to mandibular incisors) }\end{array}$ \\
\hline $\begin{array}{l}\text { 3. Relation of maxillary and mandibular incisors during voluntary } \\
\text { protrusion of jaw }\end{array}$ & Patient cannot bring mandibular incisors anterior to maxillary incisors \\
\hline 4. Interincisor distance & Less than $3 \mathrm{~cm}$ \\
\hline 5. Visibility of uvula & $\begin{array}{l}\text { Not visible when tongue is protruded with patient in sitting position } \\
\text { (e.g. Mallampati class greater than II) }\end{array}$ \\
\hline 6. Shape of palate & Highly arched or very narrow \\
\hline 7. Compliance of mandibular space & Stiff, indurated, occupied by mass, or nonresilient \\
\hline 8. Thyromental distance & Less than three ordinary finger breadths \\
\hline 9. Length of neck & Short \\
\hline 10. Thickness of neck & Thick \\
\hline 11. Range of motion of head and neck & Patient cannot touch tip of chin to chest or cannot extend neck \\
\hline
\end{tabular}

tients (64.2\%), while 29 (35.8\%) were class III/IV. Fiftyone patients $(63 \%)$ had a Wilson score of $0 / 1$, while 28 (34.6\%) had a score of $2 / 3$ and 2 patients $(2.5 \%)$ scored $\geq 4$. All the patients had an ASA algorithm $<6$ (Table 4).
Seventy-seven patients $(95.1 \%)$ were classified as Cormack-Lehane grade I/II, while 4 patients $(4.9 \%)$ were considered grade III/IV. Overall, $97.5 \%$ of the patients (n $=79$ ) were intubated at the first or second attempt; however, in one patient $(1.2 \%)$ more than two attempts were 
Table 3. Demographic characteristics of the study sample.

\begin{tabular}{|c|c|c|c|c|c|c|c|c|}
\hline \multicolumn{2}{|c|}{ Sex } & \multirow{2}{*}{ Mean age ${ }^{1}$} & \multirow{2}{*}{ Mean Height ${ }^{2}$} & \multirow{2}{*}{ Mean Weight ${ }^{3}$} & \multirow{2}{*}{ Mean $\mathrm{BMI}^{4}$} & \multicolumn{3}{|c|}{ ASA Physical Status } \\
\hline Male & Female & & & & & P1 & P2 & P3 \\
\hline 23 & 58 & 44 & 1.61 & 68 & 27 & 38 & 40 & 3 \\
\hline$(28.4 \%)$ & $(71.6 \%)$ & $(21-65)$ & $(1.47-1.86)$ & $(45-122)$ & $(18-44)$ & $(46.9 \%)$ & $(49.4 \%)$ & $(3.7 \%)$ \\
\hline
\end{tabular}

Table 4. Number of patients in the study sample according to their modified Mallampati classification and Wilson score.

\begin{tabular}{ccccc}
\hline \multicolumn{4}{c}{ Mallampati Class } & \multicolumn{3}{c}{ Wilson Score } \\
\hline I or II & III or IV & 0 or 1 & 2 or 3 & $\geq 4$ \\
$\mathrm{n}=52$ & $\mathrm{n}=29$ & $\mathrm{n}=51$ & $\mathrm{n}=28$ & $\geq 4$ \\
$(64.2 \%)$ & $(35.8 \%)$ & $(63 \%)$ & $(34.6 \%)$ & $(2.5 \%)$ \\
\hline
\end{tabular}

required and in another (1.2\%) intubation proved impossible with the use of a conventional laryngoscope, requiring the use of a gum elastic bougie (i.e. a straight, semi-rigid stylette-like device), as a guide through which intubation was achieved.

When the modified Mallampati and Cormack-Lehane classifications were correlated, it was found that, of the 52 patients who were Mallampati class I/II, 50 (96.2\%) were Cormack-Lehane grade I/II, while 2 (3.8\%) were grade III/IV. Of the 29 patients classified as Mallampati III/IV, 27 (93.1\%) were Cormack-Lehane grade I/II, while $2(6.9 \%)$ were grade III/IV. No statistically significant correlations were found $(\mathrm{p}=0.54)$ (Table 5).

All 51 patients with a Wilson score of $0 / 1$ were classified as Cormack-Lehane I/II. Of the 28 patients with a Wilson score of 2/3, $24(85.7 \%)$ were classified as Cormack-Lehane I/II, while $4(14.3 \%)$ were grade III/IV. The two patients who received a Wilson score $\geq 4$ were Cormack-Lehane grade I/II. This correlation was statistically significant $(\mathrm{p}=0.01)$ (Table 6).

When the modified Mallampati classification was correlated with the number of attempts at intubation, it was found that of the 52 patients classified as Mallampati I/II, $50(96.2 \%)$ were intubated at the first or second attempt, while in one case $(1.9 \%)$ more than two attempts were required, and in another case (1.9\%) intubation proved impossible using the conventional laryngoscope. All 29 patients classified as Mallampati III/IV were successfully intubated at the first or second attempt; with no statistically significant correlations being established $(p=0.56)$ (Table 7).

All the patients with a Wilson score of $0 / 1$ were intubated at the first or second attempt. Of the 28 patients with a Wilson score of 2/3, $26(92.9 \%)$ were intubated at the first or second attempt, while in one case $(3.6 \%)$
Table 5. Association between the modified Mallampati classification and the Cormack-Lehane grade

\begin{tabular}{cccc}
\hline Mallampati & \multicolumn{2}{c}{ Cormack-Lehane } & TOTAL \\
\hline & I or II & III or IV \\
I or II & $50(96.2 \%)$ & $2(3.8 \%)$ & 52 \\
III or IV & $27(93.1 \%)$ & $2(6.9 \%)$ & 29 \\
\hline $\mathrm{p}=0.54$. & &
\end{tabular}

Table 6. Association between the Wilson score and the Cormack-Lehane grade

\begin{tabular}{cccc}
\hline Wilson score & \multicolumn{2}{c}{ Cormack-Lehane } & TOTAL \\
\hline & I or II & III or IV & \\
0 or 1 & $51(100 \%)$ & 0 & 51 \\
2 or 3 & $24(85.7 \%)$ & $4(14.3 \%)$ & 28 \\
$\geq 4$ & $2(100 \%)$ & 0 & 2 \\
\hline
\end{tabular}

$\mathrm{p}=0.01$.

Table 7. Association between the modified Mallampati classification and the number of endotracheal intubation attempts.

\begin{tabular}{ccccc}
\hline \multirow{2}{*}{ Mallampati } & \multicolumn{3}{c}{ Intubation attempts } & TOTAL \\
\cline { 2 - 5 } & 1 or 2 & $>2$ & Failed intubation \\
\hline I or II & $50(96.2 \%)$ & $1(1.9 \%)$ & $1(1.9 \%)$ & 52 \\
III or IV & $29(100 \%)$ & 0 & 0 & 29 \\
\hline
\end{tabular}

$\mathrm{p}=0.56$

more than two attempts were required and in another case $(3.6 \%)$ intubation proved impossible with the conventional laryngoscope. The two patients with a Wilson score $\geq 4$ were intubated at the first or second attempt. Therefore, no statistically significant correlations were found ( $\mathrm{p}=0.42$ ) (Table 8 ).

The correlation between the Cormack-Lehane classification and the number of endotracheal intubation attempts showed that of the 77 patients classified as Cormack-Lehane I/II, 76 (98.7\%) were intubated at the first or second attempt, while in one case $(1.3 \%)$ more than two attempts were required to achieve successful intubation. Of the four patients classified as Cormack-Lehane III/IV, $3(85 \%)$ were intubated at the first or second at- 
tempt, while in one case (25\%) intubation proved impossible. This correlation was statistically significant $(\mathrm{p}=$ 0.0001) (Table 9).

\section{Discussion}

In anesthesiology, airway assessment at the preanesthetic consultation has been found to constitute a moment of extreme importance, and investigators in this field are constantly searching for better predictors of a difficult airway. The most commonly used tests for predicting difficult intubation include the Mallampati score, modified by Samsoom and Young [2], measurement of the sternomental and thyromental distances, the mouth opening, and the mobility of the neck and the jaw. Indexes that are less commonly used in practice, such as the Wilson score [7], and even the ASA difficult airway algorithm [5], have been studied by some authors, with conflicting results.

One of the important characteristics of the present study is that the exclusion criteria were few, resulting in the inclusion of a broad range of patients. This is important since, in clinical practice, the anesthesiologist will be confronted with a wide diversity of patients and their respective physical constitutions and anatomical variations.

In addition to standardizing the patient's position (the sniffing position), it was also important to standardize the neuromuscular blocking drug $\left(0.5 \mathrm{mg} \cdot \mathrm{kg}^{-1}\right.$ of atracurium, with a latency period of $3-5$ minutes), thus guaranteeing optimal conditions for endotracheal intubation in all the

Table 8. Association between the Wilson score and the number of endotracheal intubation attempts.

\begin{tabular}{ccccc}
\hline \multirow{2}{*}{ Wilson score } & \multicolumn{3}{c}{ Intubation attempts } & TOTAL \\
\cline { 2 - 5 } & 1 or 2 & $>2$ & Failed intubation \\
\hline 0 or 1 & $51(100 \%)$ & 0 & 0 & 51 \\
2 or 3 & $26(92.9 \%)$ & $1(3.6 \%)$ & $1(3.6 \%)$ & 28 \\
$\geq 4$ & $2(100 \%)$ & 0 & 0 & 2 \\
\hline
\end{tabular}

$\mathrm{p}=0.42$.

Table 9. Association between the Cormack-Lehane grade and the number of endotracheal intubation attempts.

\begin{tabular}{ccccc}
\hline & \multicolumn{3}{c}{ Intubation attempts } & \multirow{2}{*}{ TOTAL } \\
\cline { 2 - 4 } Cormack-Lehane & 1 or 2 & $>2$ & Failed intubation & \\
\hline I or II & 76 & 1 & 0 & 77 \\
& $98.7 \%$ & $1.3 \%$ & & 4 \\
III or IV & 3 & 0 & 1 & \\
& $75 \%$ & & $25 \%$ & \\
\hline
\end{tabular}

$\mathrm{p}=0.0001$. patients. Although the laryngoscopies were performed by residents, they were always confirmed by the chief anesthesiologist, who determined the Cormack-Lehane classification.

Shiga et al. [3] published a meta-analysis in 2005 showing that specificity and sensitivity were not high with any of the tests used alone to predict a difficult airway and that they may result in poor positive and negative predictive values. Combining these tests leads to slightly better indexes. Lundstrom et al. [4] reported similar results in a meta-analysis published in 2011 involving 177,088 patients in which only $35 \%$ of the patients in whom endotracheal intubation proved difficult had been identified as Mallampati III or IV. Adamus et al. [8] reported a sensitivity of $64.6 \%$ for the modified Mallampati classification in predicting cases of a difficult airway. In the present study, $50 \%$ of the patients $(n=2)$ in whom laryngoscopy was predicted to be difficult (Cormack-Lehane III/IV) were classified as Mallampati III/ $\mathrm{IV}$, whereas those in whom intubation indeed proved difficult (1) or impossible (1) had been classified as Mallampati I/II. Although these results were not statistically significant in the present study $(\mathrm{p}=0.54$ and $\mathrm{p}=0.56$, respectively), they show a tendency towards agreement with the previously mentioned studies.

The historical importance of the Mallampati test is indisputable. Prior to 1985 when it was created [1], investigators were already concerned with studying the airway and were aware of the need to identify reliable predictors of a difficult airway. Nevertheless, with the publication of new studies, this index has undergone criticism. Factors such as the positioning of the patient during the exam, the patient's ability to understand, the presence or absence of phonation, and pregnancy [9] may alter the patient's Mallampati class, which may explain the different incidence of Mallampati classes in the different studies. On the other hand, when studies use similar methodologies and have similar objectives, results tend to be concordant.

In the present study, the Wilson score successfully predicted $100 \%(n=4)$ of the patients in whom laryngoscopy proved difficult (Wilson $2 / 3)(p=0.01)$. This reflects the good sensitivity of this test. Specificity, however, was poor given that another 24 patients had the same Wilson score but were classified as Cormack-Lehane I/II. Furthermore, laryngoscopy proved simple in another two patients who had a Wilson score of $\geq 4$. These results appear to be in line with the findings of Domi [10], published in 2009, in which the Wilson score successfully predicted $82.5 \%$ of cases of difficult airway, a better result than the $22.5 \%$ found when the Mallampati classification was used in conjunction with the thyromental and sternomental distances. 
Since the Wilson score takes various factors and anatomical characteristics into consideration rather than just one as in the case of the Mallampati classification, sensitivity and specificity tend to be higher. Moreover, the characteristics evaluated are well defined and well described, leaving less margin for subjectivity during the exam. This brings the various studies closer methodologically, ensuring that the results are in general comparable.

Some limitations of the present study must be mentioned. The total number of patients in the sample (81) is considered small for a study involving events that are relatively rare in the general population such as the case of a difficult airway. This may have been responsible for the lack of statistical significance in some of our results. Since this is a teaching and training institute for anesthesiologists, most of the data were collected by trainee physicians. Nevertheless, although data were collected by different individuals throughout the study period, all were duly trained for this function by the authors. Because the intubations were performed by resident physicians, the number of attempts recorded may have been less in some cases if the procedure had been performed by an experienced anesthesiologist. It should be emphasized that in the patient in whom intubation was unsuccessful by conventional laryngoscopy, the anesthesiologist responsible for the case also failed to intubate the patient and was obliged to resort to the use of a gum elastic bougie to successfully conclude the procedure.

The present study concludes that the Wilson score, despite being seldom used in clinical practice, is a highly sensitive predictor of a difficult airway, although its specificity is low. Further studies with larger sample sizes are required to confirm these findings and to obtain statistically significant results for the other indexes evaluated.

\section{REFERENCES}

[1] S. R. Mallampati, S. P. Gatt, L. D. Gugino, S. P. Desai, B. Waraksa, D. Freiberger and P. L. Liu, "A Clinical Sign to Predict Difficult Endotracheal Intubation: A Prospective Study," Canadian Anaesthetists' Society Journal, Vol. 32, No. 4, 1985, pp. 429-434.

[2] G. L. Samsoon and J. R. Young, "Difficult Endotracheal Intubation: A Retrospective Study,” Anaesthesia, Vol. 42,
No. 5, 1987, pp. 487-490. doi:10.1111/j.1365-2044.1987.tb04039.x

[3] T. Shiga, Z. Wajima, T. Inoue and A. Sakamoto, "Predicting Difficult Intubation in Apparently Normal Patients. A Meta-Analysis of Bedside Screening Test Performance," Anesthesiology, Vol. 103, No. 2, 2005, pp. 429-437. doi:10.1097/00000542-200508000-00027

[4] L. H. Lundstrøm, M. Vester-Andersen, A. M. Møller, S. Charuluxananan, J. L'hermite and J. Wetterslev, "Poor Prognostic Value of the Modified Mallampati Score: A Meta-Analysis Involving 177088 Patients," British Journal of Anaesthesia, Vol. 107, No. 5, 2011, pp. 659-667. doi:10.1093/bja/aer292

[5] J. L. Apfelbaum, C. A. Hagberg, R. A. Caplan, C. D. Blitt, R. T. Connis, D. G. Nickinovich, C. A. Hagberg, R. A. Caplan, J. L. Benumof, F. A. Berry, C. D. Blitt, R. H. Bode, F. W. Cheney, R. T. Connis, O. F. Guidry, D. G. Nickinovich and A. Ovassapian, "Practice Guidelines for Management of the Difficult Airway: An Updated Report by the American Society of Anesthesiologists Task Force on Management of the Difficult Airway," Anesthesiology, Vol. 118, No. 2, 2013, pp. 251-270. doi:10.1097/ALN.0b013e31827773b2

[6] K. B. Greenland, M. J. Edwards and N. J. Hutton, "External Auditory Meatus-Sternal Notch Relationship in Adults in the Sniffing Position: A Magnetic Resonance Imaging Study," British Journal of Anaesthesia, Vol. 104, No. 2, 2010, pp. 268-269. doi:10.1093/bja/aep390

[7] M. E. Wilson, D. Spiegelhalter, J. A. Robertson and P. Lesser, "Predicting Difficult Intubation," British Journal of Anaesthesia, Vol. 61, No. 2, 1988, pp. 211-216. doi:10.1093/bja/61.2.211

[8] M. Adamus, S. Fritscherova, L. Hrabalek, T. Gabrhelik, J. Zapletalova and V. Janout, "Mallampati Test as a Predictor of Laryngoscopic View," Biomedical Papers of the Medical Faculty of the University Palacký, Vol. 154, No. 4, 2010, pp. 339-344. doi:10.5507/bp.2010.051

[9] A. Lee, L. T. Fan, T. Gin, M. K. Karmakar and W. D. Ngan Kee, "A Systematic Review (Meta-Analysis) of the Accuracy of the Mallampati Tests to Predict the Difficult Airway," Anesthesia and Analgesia, Vol. 102, No. 6, 2006, pp. 1867-1878. doi:10.1213/01.ane.0000217211.12232.55

[10] R. Domi, "A Comparison of Wilson Sum Score and Combination Mallampati, Tiromental and Sternomental Distances for Predicting Difficult Intubation," Macedonian Journal of Medical Sciences, Vol. 2, No. 2, 2009, pp. 141-144. doi:10.3889/MJMS.1857-5773.2009.0045 